\title{
Effect of Lipids on Growth Hormone Secretion in Humans
}

\author{
William G. Blackard, Edgar W. Hull, and Alfredo Lopez-S \\ From the Department of Medicine, Louisiana State University School of \\ Medicine, New Orleans, Louisiana 70112
}

A B S T R A C T To determine the effect of elevations of plasma lipids on growth hormone secretion in humans, paired insulin hypoglycemia tests and paired arginine infusion tests were performed on eight and six normal female volunteers respectively. On 1 of the 2 test days for each growth hormone stimulus, subjects were given $60 \mathrm{~g}$ corn oil (Lipomul) $3 \mathrm{hr}$ before testing followed by intravenous heparin ( $5000 \mathrm{U})$ at the time of insulin or arginine administration.

Lipomul plus heparin administration inhibited both insulin- and arginine-induced plasma $\mathrm{HGH}$ elevations with almost complete suppression of the response to arginine. The plasma HGH (human growth hormone) inhibition was associated with elevation in plasma triglycerides and inhibition of plasma FFA (free fatty acid) depression after insulin or arginine. Neither the hypoglycemic response to insulin nor the blood glucose and plasma immunoreactive-insulin responses to arginine were altered by Lipomul plus heparin administration.

In four additional subjects in whom Lipomul was given without heparin, the elevated plasma triglyceride values were not associated with suppression of arginineinduced plasma $\mathrm{HGH}$ elevations. In the same four subjects, heparin administration without Lipomul neither suppressed arginine-induced plasma $\mathrm{HGH}$ elevations nor prevented the depression in plasma FFA after arginine as much as when Lipomul plus heparin had been given. These latter observations suggest that the elevation in plasma FFA was responsible for suppression of growth hormone secretion by Lipomul plus heparin. These studies indicate a possible role of plasma FFA in regulation of growth hormone secretion.

\section{INTRODUCTION}

Growth hormone plays an important role in intermediary metabolism. Its administration results in hyperglycemia,

A presentation of this investigation was made at the meeting of the Southern Society for Clinical Investigation in New Orleans, 30 January 1971.

Received for publication 23 December 1970 and in revised form 19 February 1971. elevation of plasma free fatty acids (FFA) ${ }^{1}$ and depression of plasma amino acids (1). Two of these metabolites (glucose and amino acids) have been shown to influence growth hormone secretion in humans $(2,3)$. In a previous report from this laboratory, an inhibitory effect of lipid infusions on insulin-induced growth hormone elevations in Rhesus monkeys was shown (4). As the large quantities of soybean oil and sodium octanoate given intravenously in these studies resulted in greatly elevated plasma FFA concentrations (between $3000-5000 \mu \mathrm{Eq} /$ liter), the physiological significance of growth hormone suppression by lipids was uncertain. In order to determine whether plasma lipid elevations in a more physiological range have a regulatory role in growth hormone secretion in humans, the effect of orally administered corn oil (Lipomul) and intravenous heparin on insulin and arginine-induced growth hormone elevations in humans was tested.

\section{METHODS}

Paired insulin hypoglycemia tests and paired arginine infusions were performed on eight and six normal female volunteers respectively. The volunteers (aged 18-25) were nonobese medical students, nursing students, or secretaries who were not taking oral contraceptives. On 1 of the 2 test days for each of the growth hormone stimuli, the subjects ingested a commercially available corn oil preparation (Lipo$\mathrm{mul}^{\mathrm{R}}$ ) and received intravenous heparin in order to increase plasma FFA (5). The control and experimental tests (with Lipomul plus heparin) were done in random order and on nonconsecutive days for each growth hormone stimulus. In four additional subjects, paired arginine-infusion tests were performed to compare the effect of Lipomul alone to that of heparin alone. Lipomul without heparin was given on 1 day and heparin without Lipomul on the other test day.

The volunteers were instructed to abstain from smoking and to take nothing by mouth except water after 10:00 p.m. the night before each test. The subjects awoke at 5:00 a.m. either to remain fasting or to drink $90 \mathrm{ml}$ Lipomul containing $60 \mathrm{~g}$ corn oil. They reported to the experimental room at $7: 30$ a.m. and a slow intravenous infusion of $0.85 \% \mathrm{NaCl}$ was begun through a 19 gauge needle in an antecubital vein at 8:00 a.m. After a $15 \mathrm{~min}$ baseline period, either insulin or arginine was administered. In the insulin hypoglycemia

\footnotetext{
${ }^{1}$ Abbreviations used in this paper; HGH, human growth hormone; IRI, immunoreactive insulin; TG, triglycerides.
} 


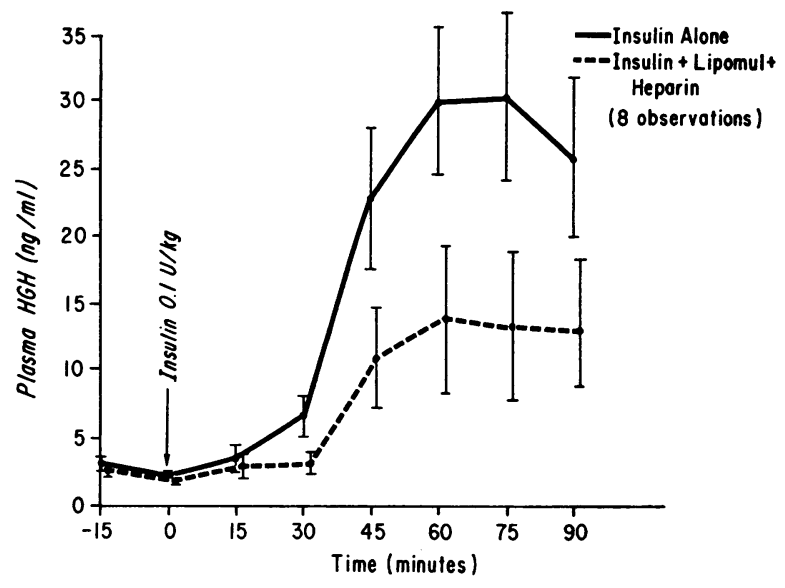

FIGURE 1 Effect of oral Lipomul and intravenously administered heparin on insulin-induced plasma HGH elevations in humans. The subjects ingested $90 \mathrm{ml}$ Lipomul $3 \mathrm{hr}$ before the first blood sample and intravenous heparin $(5000 \mathrm{U})$ was administered at zero time. Means \pm SEM are shown.

tests, regular insulin $(0.1 \mathrm{U} / \mathrm{kg})$ was given intravenously and in the arginine tests, $30 \mathrm{~g}$ L-arginine monohydrochloride as a $10 \%$ solution was infused over $30 \mathrm{~min}$. On the days of Lipomul ingestion, heparin ( $5000 \mathrm{U}$ ) was given intravenously at the time of administration of arginine or insulin. Blood samples were collected in chilled heparinized tubes every $15 \mathrm{~min}$ during the $15 \mathrm{~min}$ baseline period and for $90 \mathrm{~min}$ after the insulin had been given or the arginine infusion had been started.

Protein free filtrates for blood glucose were made from $0.2 \mathrm{ml}$ blood, and blood glucose was determined by a glucose oxidase method (6). After a portion had been taken for blood glucose determination, the blood was centrifuged and $1 \mathrm{ml}$ plasma was immediately placed in the Dole FFA ex-

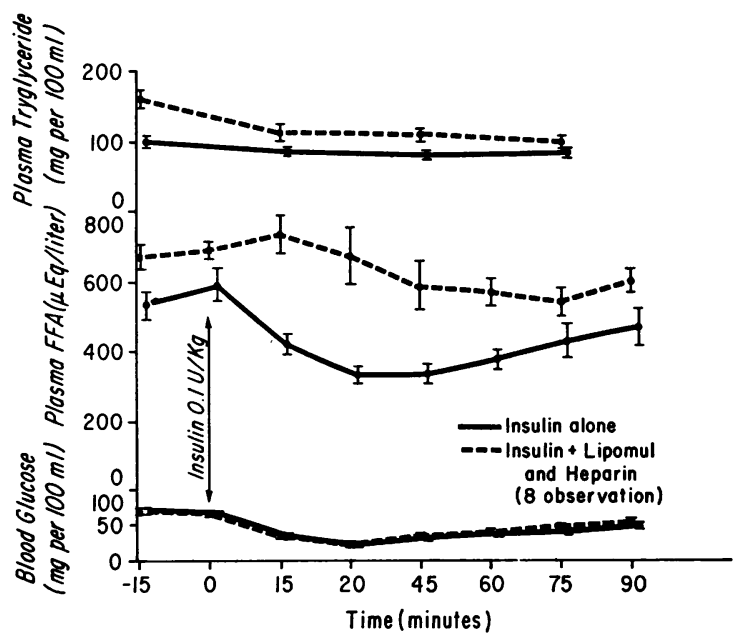

FigURE 2 Effect of oral Lipomul and intravenously administered heparin on plasma TG and FFA and blood glucose before and after insulin administration. Means ISEM are shown. traction mixture to eliminate as much as possible extracorporeal hydrolysis of triglycerides. Plasma FFA was measured by a modification of the Dole procedure (7). Plasma triglycerides were determined automatically by the method of Kessler and Lederer (8). Plasma HGH was determined by a modification of the double antibody radioimmunoassay method of Schalch and Parker (9). Plasma IRI (immunoreactive insulin) was also determined by a double antibody radioimmunoassay method (10). Heparin and Lipomul added to plasma so as to constitute $10 \%$ of the volume (higher than any concentrations that would have occurred in vivo) did not alter significantly IRI or $\mathrm{HGH}$ values from that obtained when the same plasma sample was diluted by $10 \%$ with buffer.

L-arginine monohydrochloride as a $10 \%$ solution was purchased from Cutter Laboratories, Inc., Berkeley, Calif. Lipomul was purchased from The Upjohn Company, Kalamazoo, Mich. Sodium heparin (Liquaemin Sodium "100") was purchased from Organon Inc., West Orange, N. J.

\section{RESULTS}

Fig. 1 shows the effect of treatment with Lipomul plus heparin on insulin-induced plasma $\mathrm{HGH}$ elevations in eight normal female volunteers. Plasma $\mathrm{HGH}$ rose significantly less during the insulin tests in which the subjects were given Lipomul plus heparin than in the control test in which insulin alone was given $(P<0.02$ at $45,60,75$, and $90 \mathrm{~min}$ ). Administration of Lipomul plus heparin to the subjects also resulted in increased plasma triglyceride concentrations without any significant change in the hypoglycemic response to insulin (Fig. 2). Plasma FFA were elevated when Lipomul plus heparin had been given and did not fall after insulin injection to the extent seen when insulin was given alone.

Lipomul plus heparin administration also inhibited the arginine-induced plasma $\mathrm{HGH}$ elevations in six normal female volunteers (Fig. 3). Plasma HGH concentrations were significantly less at $45,60,75$, and 90

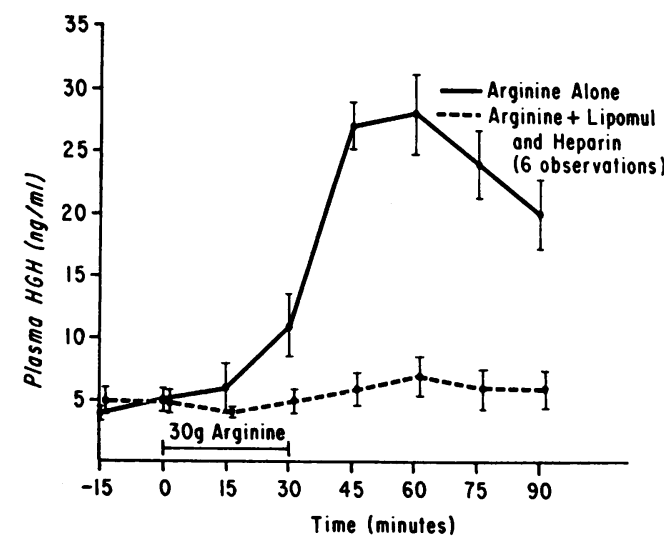

FIGURE 3 Effect of oral Lipomul and intravenously administered heparin on arginine-induced plasma $\mathrm{HGH}$ elevations in humans. Means \pm SEM are shown. 
min when Lipomul plus heparin were given than in the control experiments $(P<0.01$ at each interval). After the administration of Lipomul plus heparin, plasma triglycerides were increased by approximately $50 \%$ (Fig. 4). Plasma FFA concentrations were also increased and did not fall after arginine infusion to the degree seen in the control experiments with arginine alone. The alterations in plasma lipids caused by oral Lipomul and intravenous heparine administration did not significantly alter the blood glucose or plasma IRI response to arginine (Fig. 5).

Paired arginine-infusion studies were performed on four additional subjects. The subjects received Lipomul alone before one of the infusions and heparin alone with the other. The plasma HGH responses to arginine were similar during both tests (Fig. 6) and did not appear inhibited compared to the response when arginine alone was administered to other subjects (Fig. 3). Plasma triglycerides were elevated by Lipomul but the plasma FFA and blood glucose responses to arginine were similar when either Lipomul alone or heparin alone was given (Fig. 6). In experiments with Lipomul alone or heparin alone the maximal mean depressions in plasma FFA after arginine, were to 54 and $68 \%$ of the baseline value (zero time) respectively, whereas, when Lipomul plus heparin was given, the maximal mean fall in FFA was to only $87 \%$ of the baseline value. Arginine infusions without Lipomul or heparin resulted in a maximal mean decrease in plasma FFA to $55 \%$ of the baseline value.

\section{DISCUSSION}

Growth hormone plays a central role in intermediary metabolism and in this respect resembles insulin more than it does the other anterior pituitary hormones. The same major metabolites which affect insulin secretion also affect growth hormone secretion. Glucose and

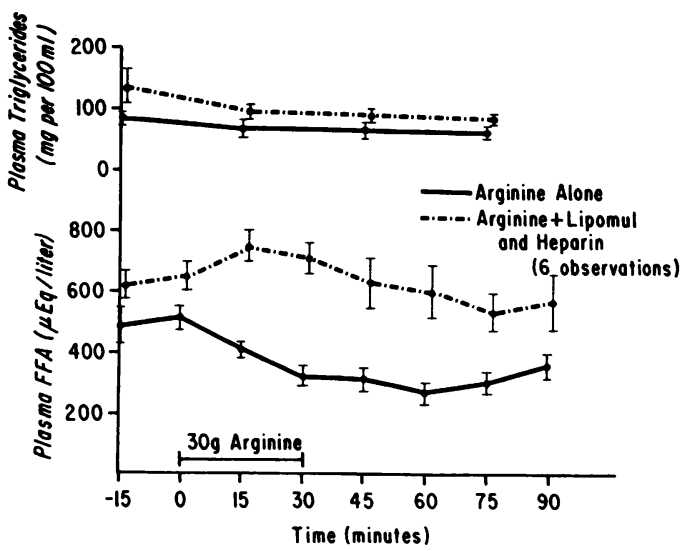

FIGURE 4 Effect of oral Lipomul and intravenously administered heparin on plasma FFA and TG before and after arginine infusion. Means \pm SEM are shown.

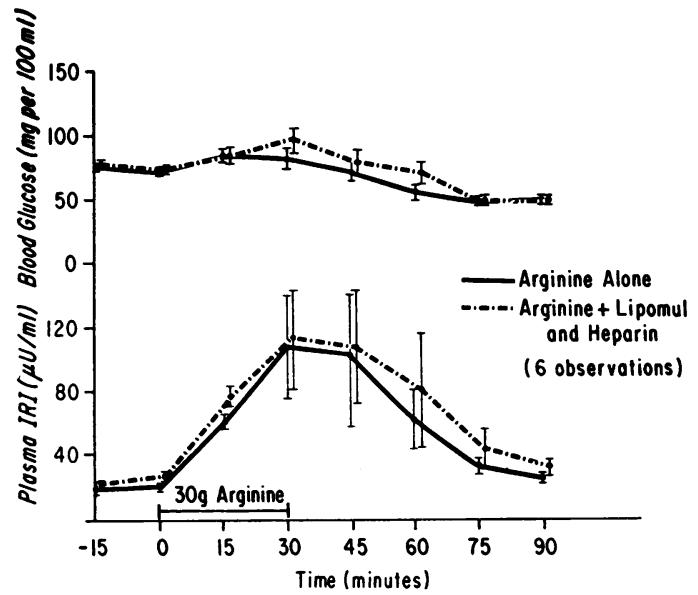

Figure 5 Effect of oral Lipomul and intravenously administered heparin on arginine-induced blood glucose and plasma IRI elevations. Means \pm SEM are shown.

amino acids have previously been demonstrated to have regulatory roles in growth hormone secretion $(2,3)$. The present investigation corroborates in humans our previously reported findings in Rhesus monkeys, that lipids have an inhibitory effect on growth hormone secretion (4). In this study, suppression of insulin and arginine-induced growth hormone elevations by Lipomul plus heparin occurred with increases in plasma triglycerides and FFA in a range found in normal individuals under different physiological conditions.

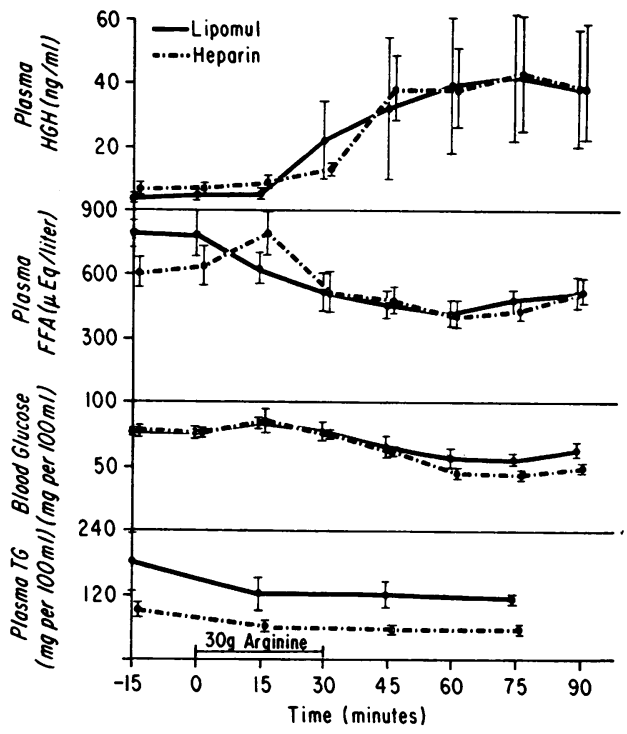

Figure 6 Effect of Lipomul or heparin alone on plasma HGH, FFA, TG, and blood glucose before and after arginine infusion. Means \pm SEM for the four paired observations are shown.

Lipids and Growth Hormone Secretion 
The suppressive effect of Lipomul plus heparin on growth hormone secretion correlates better with alterations in plasma FFA than in plasma triglycerides. In experiments in which either Lipomul or heparin was given to subjects receiving an arginine infusion, the growth hormone response was similar to that observed when arginine was administered alone. Since ingestion of Lipomul without intravenous heparin resulted in plasma triglyceride concentrations as high as those when Lipomul plus heparin were given, a suppressive effect of plasma triglycerides on growth hormone secretion seems unlikely. Furthermore, heparin alone did not inhibit arginine-induced plasma $\mathrm{HGH}$ elevations, nor did it prevent the fall in plasma FFA to the extent observed when Lipomul and heparin were given together. Additional studies from this and other laboratories support our contention that the suppressive effect of lipids on growth hormone secretion may be due to the FFA component. Previous investigations in Rhesus monkeys demonstrated a suppressive effect of sodium octanoate on growth hormone secretion (4). In addition, the unmasking of a stimulatory effect of epinephrine on growth hormone secretion by simultaneous administration of the beta adrenergic blocker propranolol suggests that either plasma FFA elevation or opposing beta receptor stimulation is responsible for the failure of epinephrine alone to increase plasma HGH (11). Also, Irie, Sakuma, Tsushima, Shizume, and Nakao have suggested that plasma HGH elevations occurring after nicotinic acid administration were related to a fall in plasma FFA since both the plasma FFA depression and HGH elevation could be inhibited by heparin (12). Direct proof that the suppressive effect of lipids on growth hormone secretion in humans is due to FFA rather than to some other factor, will depend on studies performed when satisfactory means of physiologically administering free fatty acids to humans is available.

The delicate interrelationships between the various metabolites regulating growth hormone secretion make it difficult to determine which of the factors are most significant in the fine control of growth hormone secretion. For example, the plasma $\mathrm{HGH}$ response to insulin could theoretically be due to a depression in FFA as well as to hypoglycemia. The observation that the plasma $\mathrm{HGH}$ response to insulin can be prevented by administering intravenous glucose (13) could be interpreted as indicating that hypoglycemia is more responsible for stimulating growth hormone secretion. However, the present investigations showing inhibition of insulin-induced growth hormone elevations by lipids suggest that depression in plasma FFA might also be an important stimulus for growth hormone secretion after insulin administration. The almost complete inhibition of arginine-induced plasma $\mathrm{HGH}$ elevations by modest alterations in plasma lipids when Lipomul plus heparin are given, justifies speculation as to whether arginine stimulates growth hormone secretion directly or, in part, by its effect on FFA. As arginine causes hyperglycemia, changes in blood glucose concentration certainly are not responsible for arginine-induced plasma $\mathrm{HGH}$ elevations.

An inhibitory effect of FFA on growth hormone secretion might have been anticipated from information available on insulin and growth hormone homeostasis. With the exception of amino acids, which stimulate both insulin and growth hormone secretion, many of the regulatory factors for insulin secretion also affect growth hormone secretion but in reciprocal fashion. Hyperglycemia and hypoglycemia have opposite effects on insulin and growth hormone secretion. The adrenergic control mechanisms demonstrated for insulin and growth hormone secretion are also reciprocal (14). Alpha adrenergic receptor stimulation inhibits insulin secretion but enhances growth hormone secretion whereas beta receptor stimulation increases insulin secretion but inhibits growth hormone secretion. Although direct evidence for an effect of FFA on insulin secretion in man is lacking, FFA have been shown to stimulate insulin secretion in the dog (15). The inhibitory effect of FFA on growth hormone secretion suggested in this report further corroborates the reciprocal relationship between insulin and growth hormone.

\section{ACKNOWLEDGMENTS}

We wish to acknowledge the capable technical assistance of Mrs. Thelma Hinson.

This work was supported by grants AM 10151 and HE13205 from the National Institutes of Health.

\section{REFERENCES}

1. Snipes, C. A. 1968. Effects of growth hormone and insulin on amino acid and protein metabolism. Quart. Rev. Biol. 43: 127

2. Roth, J., S. M. Glick, P. Cuatrecasas, and C. S. Hollander. 1967. Acromegaly and other disorders of growth hormone secretion. Ann. Intern. Med. 66: 760.

3. Knopf, R. F., J. W. Conn, S. S. Fajans, J. C. Floyd, E. M. Guntsche, and J. A. Rull. 1965. Plasma growth hormone response to intravenous administration of amino acids. J. Clin. Endocrinol. Metab. 25: 1140.

4. Blackard, W. G., C. T. Boylen, T. C. Hinson, and N. C. Nelson. 1969. Effect of lipid and ketone infusions on insulin-induced growth hormone elevations in rhesus monkeys. Endocrinology. 85: 1180.

5. Schalch, D. S., and D. M. Kipnis. 1965. Abnormalities in carbohydrate tolerance associated with elevated plasma nonesterified fatty acids. J. Clin. Invest. 44: 2010.

6. Saifer, A., and S. Gerstenfeld. 1958. The photometric microdetermination of blood glucose with glucose oxidase. J. Lab. Clin. Med. 51: 448.

7. Trout, D. L., E. H. Estes, Jr., and S. J. Friedberg. 1960. 
Titration of free fatty acids of plasma: a study of current methods and a new modification. J. Lipid Res. 1: 199.

8. Kessler, G., and H. Lederer. 1966. Fluorometric measurement of triglycerides. In Automation in Analytical Chemistry. L. T. Skeggs, Jr., editor. Mediad, New York. 341.

9. Schalch, D. S., and M. L. Parker. 1964. A sensitive double antibody immunoassay for human growth hormone in plasma. Nature (London). 203: 1141.

10. Morgan, C. R., and A. Lazarow. 1963. Immunoassay of insulin: two antibody system. Plasma insulin levels of normal, subdiabetic and diabetic rats. Diabetes. 12: 115.

11. Blackard, W. G., and G. J. Hubbell. 1970. Stimulatory effect of exogenous catecholamines on plasma HGH con- centrations in presence of beta adrenergic blockade. Metab. (Clin. Exp.). 19: 547.

12. Irie, M., M. Sakuma, T. Tsushima, K. Shizume, and K. Nakao. 1967. Effect of nicotinic acid administration on plasma growth hormone concentration. Proc. Soc. Exp. Biol. Med. 126: 708.

13. Roth, J., S. M. Glick, R. S. Yalow, and S. A. Berson. 1963. Hypoglycemia: a potent stimulus to secretion of growth hormone. Science (Washington). 140: 987.

14. Blackard, W. G., and S. A. Heidingsfelder. 1968. Adrenergic receptor control mechanism for growth hormone secretion. J. Clin. Invest. 47: 1407.

15. Crespin, S. R., W. B. Greenough, III, and D. Steinberg. 1969. Stimulation of insulin secretion by infusion of free fatty acids. J. Clin. Invest. 48: 1934. 